Seção de Tradução

Translation 



\title{
O PÁrodo do Rei Édipo de SóFocles: InTROdução E TRADUÇÃo
}

\section{The parodos of Sophocles' Oedipus: Introduction and Translation}

\author{
Flávio Ribeiro de Oliveira*
}

INTRODUÇÃo

o párodo de uma tragédia grega é o canto inicial do Coro, entoado quando ele, fazendo evoluções de dança, entra na orkhéstra. Uma das funções dos cantos corais trágicos - satisfeita exemplarmente no párodo do Rei Édipo de Sófocles - consistia em impor profundidade emocional a uma situação quando as circunstâncias factuais já eram conhecidas pelo espectador ${ }^{1}$.

No Rei Édipo (não há indícios exatos de sua data de composição, mas admite-se que tenha sido pouco antes de 425 a.C.), o Coro é composto por anciãos tebanos e entoa seu canto de entrada após o prólogo em que Édipo, o Sacerdote e Creonte dialogam, situando, para o espectador, a ação da peça. Diante do palácio do rei Édipo, o sacerdote de Zeus e um grupo de crianças assumem atitude de súplica e imploram ao rei que tome medidas para afastar a peste que assolava a cidade. Édipo tranquiliza os suplicantes e anuncia que já tomou providências: enviou Creonte, seu cunhado, a Delfos, para que consultasse o oráculo. Pouco depois Creonte chega e transmite aos presentes as instruções do oráculo:

"rei Febo ordena abertamente que expulsemos da terra a podridão nutrida neste solo,

e que não a nutramos a ponto de se tornar incurável" (versos 96-8)

*Unicamp

1 Cf. R.D. Dawe, Sophocles - Oedipus Rex. Edited by R. D. Dawe. Cambridge, University Press, 1982, pág. 105. 
A podridão a que faz referência o oráculo de Febo (Apolo) está relacionada com o assassinato de Laio, o último rei de Tebas antes de Édipo: contaminava moral e religiosamente a cidade e provocava a peste o fato de que os assassinos (no plural, pois os tebanos acreditavam que Laio tinha sido morto por um bando de ladrões) do antigo rei ainda viviam na cidade, impunes. A palavra oracular trazida por Creonte permite esperança: já se sabe qual é a causa da epidemia que afligia Tebas. Basta encontrar e castigar, com exílio ou morte, os assassinos. Édipo, rei justo e escrupuloso, assume a responsabilidade de encontrar e punir os culpados.

Édipo e Creonte entram no palácio; o sacerdote e os suplicantes também deixam a cena. É neste ponto que entra na orkhéstra o Coro de anciãos tebanos, entoando o párodo.

A esperança ensejada pelo oráculo e manifestada no prólogo desde o verso 87 ecoa nas primeiras palavras do Coro (veja-se o adjetivo haduepès, "dulcíloquo", aplicado à palavra do oráculo no primeiro verso do párodo); contudo, a ansiedade logo se impõe e passa a dar o tom do canto. o Coro teme: o sentido das palavras do deus não é evidente para os anciãos ${ }^{2}$. o Coro pede, então, à própria palavra oracular que esclareça seu sentido e, em seguida, manifesta sua apreensão (primeira estrofe). o temor que sente o levará, nas estrofes e antístrofes seguintes, a uma série de invocações de deuses, de caráter fortemente hierático (a estrutura do párodo aproxima-se muito da de um hino cultual $^{3}$ ), intercaladas com patética descrição da peste e de seus efeitos sobre a cidade.

$\mathrm{Na}$ primeira antístrofe, o Coro invoca a tríade Atena, Ártemis e Apolo. Anima o Coro o fato de que, em ocasiões anteriores nas quais a cidade estava ameaçada, esses deuses, convocados, compareceram: a estrutura da invocação é análoga àquela presente na ode a Afrodite de

2 Alguns comentadores, como Jebb (Sophocles - Oedipus Tyrannus. Edited with Introduction and Notes by Sir Richard C. Jebb; Cambridge, University Press, 1993, pág. 25), entendem que o Coro não ouviu a resposta trazida por Creonte: ele apenas saberia que este foi enviado em missão a Delfos. Outros comentadores discordam (por exemplo, Jean Bollack, L'Oedipe Roi de Sophocle. Le texte et ses Interpretations. Commentaire. Première Partie. Lille, Presses Universitaires de Lille, 1990, pág. 86; R. D. Dawe, Sophocles - Oedipus Rex. Edited by R. D. Dawe. Cambridge, University Press, 1982, págs. 105-106).

${ }^{3}$ Cf. W. Ax, Die Parodos des Oidipus Tyrannos. Hermes, 67, 1932, págs. 413-437. 
Sapho (frag. 1 Voigt).

A segunda estrofe e a segunda antístrofe descrevem a peste que assola a cidade e os sofrimentos do povo tebano: retomam, com acentos líricos, o breve relato que fizera o sacerdote no prólogo (versos 19-30). No fim da segunda antístrofe o Coro recomeça as invocações divinas, dirigindose à filha de Zeus (segundo a maior parte dos comentadores, trata-se de Atena; segundo outros, seria a própria palavra oracular mencionada no primeiro verso do párodo).

$\mathrm{Na}$ terceira estrofe o Coro roga que Ares (deus da carnificina, aqui identificado como causador da peste) seja banido de Tebas: que os raios de Zeus o aniquilem! A terceira antístrofe conclui o párodo com nova invocação de uma tríade divina: Apolo, Ártemis e Dioniso. o Coro deseja que as flechas do primeiro e que as tochas dos dois últimos derrotem Ares, responsável pela peste, deus desonrado entre os deuses.

A excelência deste canto coral advém do fato de que seu caráter cultual se conforma perfeitamente às necessidades da ação dramática ${ }^{4}$ : dadas no prólogo as circunstâncias factuais, o Coro as retoma e, num canto solene e grave, lhes dá densidade emocional.

\author{
REI ÉDIPO - PÁRODO \\ tradução de Flávio Ribeiro de Oliveira - IEL - Unicamp
}

CORO

estrofe 1

Ó palavra dulcíloqua de Zeus ${ }^{5}$, qual és, que da aurífica Pito ${ }^{6}$ vieste à resplendente Tebas?

${ }^{4}$ Cf. J.C. Kamerbeek, The Plays of Sophocles. Commentaries. Part IV. The Oedipus Tyrannus. Leiden, Brill, 1967, pág. 56.

5 O Coro se dirige à própria palavra do oráculo, enviada de Delfos a Tebas, e lhe pergunta qual é seu sentido. Aqui, refere-se a ele como oráculo "de Zeus", pois, numa perspectiva teológica, é a justiça de Zeus que se manifesta através do oráculo de seu filho Apolo.

${ }^{6}$ Delfos. Édipo enviara Creonte a Delfos, para consultar o oráculo de Apolo (Febo). Pito é o antigo nome de Delfos: ali Apolo era venerado com o epíteto "pítico", desde que matara a serpente Píton. 
Estou tenso em meu ânimo medroso,

tremendo de receio,

ó uivável délio Peã ${ }^{7}$,

temente a ti: que tributo

novo ou periódico

exigirás de mim desta vez?

Dize-me, áurea filha da esperança,

voz imortal ${ }^{8}$ !

Conclamo-te primeiro, filha de Zeus,

Atena imortal,

e tua irmã terratenente,

Ártemis, assentada no ínclito trono

cíclico da praça ${ }^{9}$,

e Febo sagitífero, eia,

mostrai-vos a mim, tríade mortífuga:

se outrora, quando desastre precedente

se atirava sobre a cidade,

eliminastes a flama do flagelo ${ }^{10}$,

vinde também agora!

${ }^{7}$ Peã era um deus médico que foi assimilado a Apolo. 0 termo, aqui, refere-se a Apolo. "Délio", pois Apolo nasceu na ilha de Delos. "Uivável" traduz o adjetivo iéïos, que significa "que se pode evocar uivando ié" (ié é um grito ritual associado ao culto de Apolo). Uma etimologia popular associava o adjetivo iéïos ao radical do verbo iáomai, "curar" (de fato, Apolo é o deus que cura). O mesmo adjetivo aparece mais tarde neste canto coral para se referir às dores do parto (que produzem uivos, que fazem as mulheres gritar ié).

${ }^{8}$ A "voz imortal" é a palavra oracular (definida como "palavra dulcíloqua de Zeus" no primeiro verso do párodo). É filha da esperança, pois era a esperança de salvação que levava os homens a consultar oráculos.

${ }^{9} \mathrm{Na}$ praça (agorá) de Tebas, havia um templo dedicado a Ártemis. A interpretação do adjetivo "cíclico" é controversa. Alguns comentadores entendem que o "trono cíclico" designa a própria praça, que teria formato circular; outros entendem que a expressão se refere a um templo de forma redonda dedicado à deusa na praça de Tebas.

${ }^{10}$ A "flama do flagelo" é a Esfinge, que assolava Tebas antes do advento de Édipo: este, com a ajuda dos deuses, livrou dela os tebanos. 
Ai ai, suporto inumeráveis flagelos!

Todo o meu povo está doente

e não há arma de raciocínio

com a qual se defender,

pois nem cresce fruto da terra gloriosa,

nem nos partos mulheres emergem das dores uivantes.

Podes ver um atrás do outro, como aves alipotentes,

com mais força que o fogo infrene,

atirar-se para as ribas do deus crepuscular ${ }^{11}$,

inumeráveis: a cidade perece.

Sem dó sua prole jaz no solo,

mortífera ${ }^{12}$, ilastimada.

Entretanto esposas e grisalhas mães,

às ribas dos altares, de todos os lados,

plangem súplices por tristes dores.

O peã ${ }^{13}$ lampeja e, no mesmo canto ${ }^{14}$, a voz gemente:

por isso, ó áurea filha de Zeus ${ }^{15}$,

envia a nós o pulcro amparo!

${ }^{11}$ Hésperos significa a) vespertino, b) ocidental. O ocidente é a região do crepúsculo, onde o sol se põe. É no extremo ocidente da terra que Homero situava a morada dos mortos, onde reinava Hades, o deus do ocidente / do crepúsculo. As ribas em questão são as do Aqueronte, rio que circundava o país dos mortos.

${ }^{12}$ A prole da cidade, que jaz morta, é também mortífera, pois o contato com os que morreram de peste contagia os vivos.

13 "Peã", acima, designava Apolo (cf. a nota 7); aqui, contudo, designa os cantos rituais entoados em honra de Apolo: o termo é ao mesmo tempo o nome do deus e o canto com o qual esse deus é saudado. Na frase "o peã lampeja e, no mesmo canto, a voz gemente" temos uma metáfora sinestésica, em que substantivos que designam sons (peã, voz) regem um verbo que designa uma ação luminosa (lampejar).

14 O adjetivo hómaulos é ambíguo: pode significar a) "consonante", "uníssono", "que soa ao junto", se entendermos que o segundo elemento provém de aulós (instrumento musical de sopro), ou b) "que está no mesmo lugar", "que ocupa o mesmo espaço", "vizinho", se considerarmos que o segundo elemento provém de aulé ("pátio"). A tradução "no mesmo canto" conserva a ambiguidade.

${ }^{15}$ Refere-se provavelmente a Atena. Alguns, contudo, entendem que a "áurea filha de Zeus" é a "palavra dulcíloqua de Zeus", a palavra oracular personificada (cf. nota 5). 
E Ares $^{16}$ devastador, que agora sem bronze de escudos

me inflama avançando circundado de gritos, dê as costas em retrocedente fuga da pátria!

Bons ventos o levem

à vasta morada de Anfitrite

ou ao porto inóspito, às vagas da Trácia ${ }^{17}$ !

No fim, o que a noite deixa

o dia ataca.

A ele, ó tu que reges o poder

dos igníferos relâmpagos,

ó Zeus pai, aniquila sob teu raio!

antistrofe 3

Rei Lício ${ }^{18}$, eu queria que fossem despedidos

das cordas auritrançadas

teus dardos indomáveis,

amparo anteposto,

bem como os fachos igníferos de Ártemis,

com os quais ela percorre os lícios montes!

E conclamo o aurimitrado ${ }^{19}$,

${ }^{16}$ Ares, deus da guerra e da carnificina, é aqui identificado com o efeito devastador da peste. Malerós (“devastador”) é, em Homero, epíteto do fogo (a propósito da imagem, vejam-se, no prólogo, os versos 27 e 28 , em que o sacerdote se refere à peste como "deus ignífero")

${ }^{17}$ Anfitrite era uma deusa marinha, esposa de Posídon. A expressão "vasta morada de Anfitrite" designa o oceano Atlântico. "Porto inóspito" e "vagas da Trácia" designam o Ponto Euxino (atual mar Negro) junto à região da Trácia. O Coro deseja que Ares seja levado para bem longe de Tebas, para as regiões mais remotas da Terra, que delimitavam o mundo conhecido.

${ }^{18}$ Lýkeios é um epíteto do deus Apolo que pode significar: a) "relativo à luz" (do radical de leukós, "brilhante"); b) "relativo aos lobos" (do radical de lýkos, "lobo"; referência a outro epíteto de Apolo, lykoktónos, "matador de lobos"); c) "da Lícia" (região da Ásia menor). Cinco versos abaixo, o adjetivo lýkios, muito próximo de lýkeios pela forma, é aplicado às montanhas que percorre Ártemis, irmã de Apolo: ali significa "da Lícia" (mas não se pode excluir a hipótese de haver, neste contexto, uma contaminação semântica entre ambos).

${ }^{19}$ Baco usava uma mitra (faixa de origem oriental para prender os cabelos) de ouro. 
o epônimo desta terra ${ }^{20}$, Évio ${ }^{21}$ Baco víneo, único guia das Mênades ${ }^{22}$, a avançar inflamando-se, com tocha esplendente, contra o deus desonrado ${ }^{23}$ entre os deuses!

TEXTo GREGo (estabelecido a partir de edição de Jean Bollack)

ஸे $\Delta$ Iò

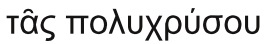

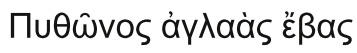

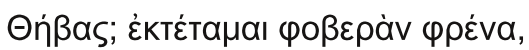

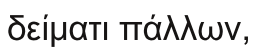
ịı́ı $\Delta \alpha \dot{\alpha} \wedge \varepsilon$ Пaı́à,

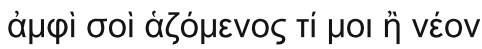

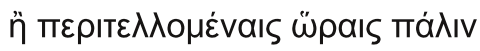

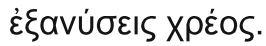

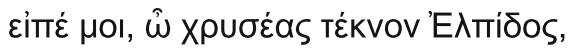

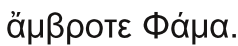

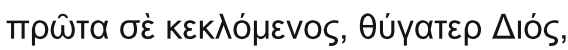

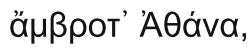

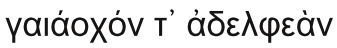

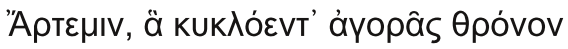

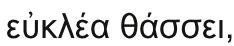

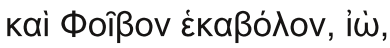

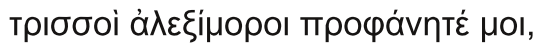

${ }^{20}$ Epónimos é aquele que dá seu nome a uma região: Tebas era também chamada de Bakkheía (do nome do deus, Bákkhos), pois Sêmele, mãe de Baco, era tebana.

${ }^{21}$ Em grego, eúios significa "que se pode evocar gritando evoé (euô̂l)". Euồ é um grito ritual associado ao culto de Baco.

${ }^{22}$ As Mênades eram mulheres em transe que faziam parte do cortejo de Baco.

${ }^{23} \mathrm{O}$ deus que não tem honra entre os outros deuses é Ares. 


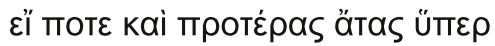

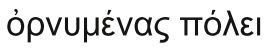

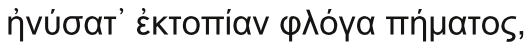

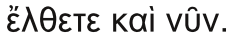

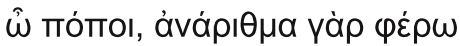

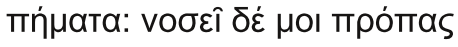

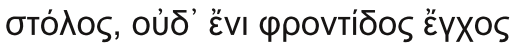

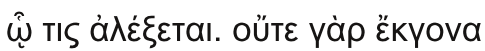

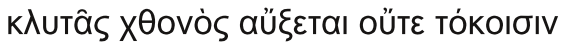

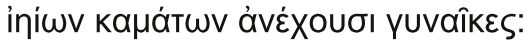

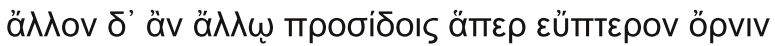

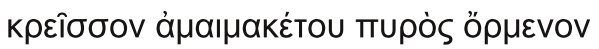

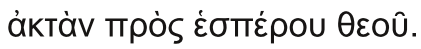

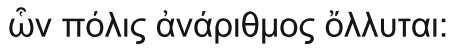

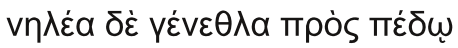

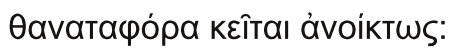

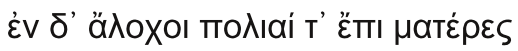

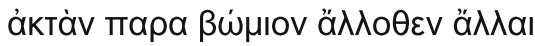

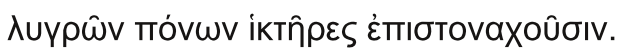

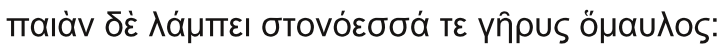

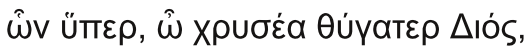

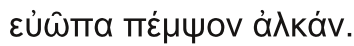

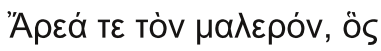

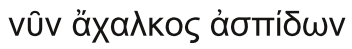

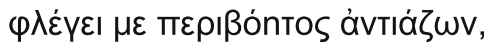

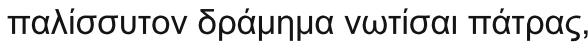

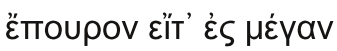

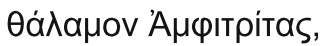

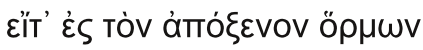

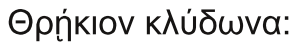

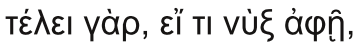

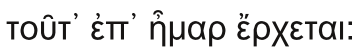




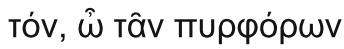

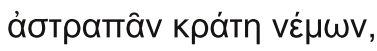

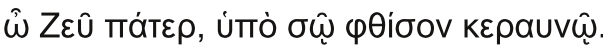

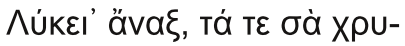

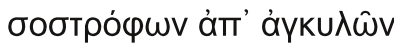

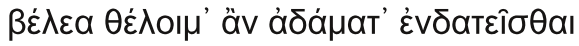

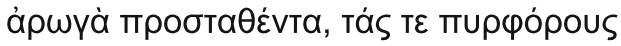

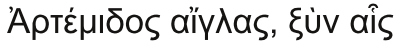

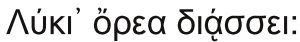

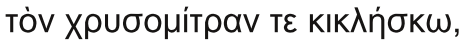

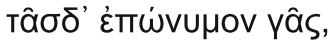

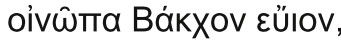

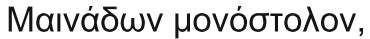

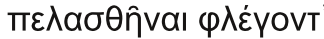

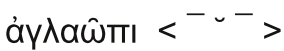

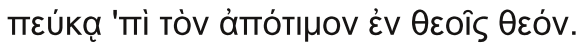

Submetido em: 16/06/2011

Aceito em: 25/07/2011 
